\title{
Aneuploidy in Wild Picris babylonica (Asteraceae) in Kuwait
}

\author{
G. A. Malallah, T. A. Attia and M. Masood \\ Kuwait University, Faculty of Science, Department of Biological Sciences, \\ P.O. Box 5969, Safat-13060, Kuwait \\ Accepted April 23, 2001
}

\begin{abstract}
Summary A cytological study of wild Picris babylonica in Kuwait revealed several aneuploids; monosomic $(2 n=9)$, trisomic $(2 n=11)$ and tetrasomic $(2 n=12)$ in addition to the prevailing euploidy condition $(2 n=10)$. Morphological features were not appreciably different among the aneuploid plants. Karyotype analyses showed that the first chromosome pair was probably involved either in trisomic or monosomic plants. Two univalents plus 4 bivalents were also detected in some analyzed PMC's. The possible origion of aneuploids and their probable relevance in speciation and evolution in plants are discussed.
\end{abstract}

Key words Aneuploidy, Kuwaiti flora, Picris babylonica.

Picris babylonica Hand.-Mazz., an annual herb that normally flowers and fruits between February and May, is widely distributed in Kuwait, Iraq and Saudi Arabia. A detailed description and comprehensive morphological study of P. babylonica was provided by Al-Rawi (1987). Malallah et al. (1997) and Malallah and Brown (1999) made the first cytological studies on this species, showing that the somatic number of this species is 10 and the gametic number is 5 with description of the 10 chromosomes.

Aneuploidy, a common phenomenon in plants, occurs when the chromosome number is not the exact multiple of basic number $(x)$ of the true diploids. In the case of chromosomal excess many plant species, particularly the primitive or the wild plant forms, can generally tolerate a few additional chromosomes (Khush 1970, Rick 1971, Rick and Notani 1961). On the other hand, most of the diploid plants with chromosomal decrease (monosomics, $2 n-1$ ) are weak and hardly viable, although in few cases as in tomato and maize they can be sufficiently vigorous to flower and even reproduce. Aneuploidy arises mainly through deviating meiosis (Khush and Rick 1966, Weber 1983) either spontaneously (Khush 1973) or in response to treatments with chemicals or radiation (Wang and Iwata 1996). It is an important phenomenon not only because of its application in plant cytogenetical studies but also due to its probable role as one of the evolutionary mechanisms in the plant. The present study shows the finding of aneuploidy condition, and other meiotic peculiarities in $P$. babylonica. The possible origin and significance of aneuploidy in speciation and evolution in plants are discussed.

Materials and methods

Seeds and flower buds of Picris babylonica Hand.-Mazz. were collected from groups of plants growing at various locations in Kuwait (the area of Kuwait is $17818 \mathrm{~km}^{2}$ approx.) during the years 1993, 1998 and 1999. Dr. M. Mathew and M. Al-Doseri (Herbarium of Faculty of Science, Kuwait University, KTUH) made the identification. Voucher specimens were deposited at KTUH. No morphological differences were noticed among the collected plants, so all plants were treated the same during the preparation for chromosome analysis.

Young flower buds were fixed and preserved in Carnoy's solution (ethanol: glacial acetic acid, $3: 1 \mathrm{v} / \mathrm{v})$. The smears of anthers were stained with aceto-orcein. Seeds were germinated in a con- 
trolled growth chamber, the root tips were collected and treated with $0.05 \%$ colchicine for $3 \mathrm{~h}$ at room temperature. The root tips were then fixed in Carnoy's solution and preserved in $70 \%$ ethanol in a refrigerator until use. For chromosome analysis, the conventional squash method was performed using the stain aceto-carmine. Karyotype analyses were based on at least 5 cells with wellspread chromosomes. Photo-ideograms were prepared by cutting out individual chromosomes and arranging them in a descending order on the basis of total length, centromere position, arm ratio and existence of a satellite. Standard error (S.E.) was estimated.

\section{Results}

In the majority of analyzed mitotic and meiotic cells, Picris babylonica exhibited a diploid chromosome number of 10 (Figs. 1a, 2, 7). This value was recorded from large number of plants during the present and previous work. The karyotype of $2 n=10$ plants consisted of one pair of subterminal, 3 pairs of submetacentric and one pair of metacentric chromosomes (Fig. 1a, Table 1). In addition, aneuploid plants of $P$. babylonica with chromosome numbers of 11 and 9 were observed. In analyzed seedlings, the trisomic condition $(2 n=11)$ was detected in the cells of the root tips of several plants such as those shown in Figs. 3 and 4, while the monosomic condition $(2 n=9)$ was observed in all cells of only one root tip (Fig. 5). These aneuploid cells were found in samples collected from the same locality (Shuwaikh University Campus, $5 \mathrm{~km}$ north of Kuwait City in 1998-1999). The tetrasomic number of $2 n=12$ (Fig. 6) was previously detected in root tip samples collected from another locality (Qurtoba, $8 \mathrm{~km}$ east of Kuwait City in 1993 unpublished data). Another plant collected from the same locality in 1998 showed 6 bivalents at metaphase I (photo is not shown) confirming the tetrasomic condition of $2 n=12$. Karyotype analyses strongly suggested that the extra chromosome in cells with $2 n=11$ and the missing chromosome in cells with $2 n=9$ belong to the first pair (Table 1, Fig. 1b-e). This has been based on the total chromosome length and the presence of the satellite in the studied plants of both aneuploid cases. In the analyzable pollen mother cell with $2 n=10$, although meiosis took place normally with complete pairing in most cases (Fig. 7), in few cells 2 univalents (about $15 \%$ of the analyzed pollen mother cells) were observed in diplotene or diakinesis of some plants indicating synaptic failure of chromosomes (Fig. 8).

It is worthy to mention that this species is commonly grown in many localities in Kuwait and no morphological differences were observed among the plants during every season collection.

\section{Discussion}

The basic chromosome number of the genus Picris was reported to be $x=5$ (Darlington and Wylie 1955). The gametic number of $P$. saharae from Kuwaiti flora was found to be $n=5$ (El-Bayoumi 1973). The name $P$. saharae was wrongly applied in earlier literature in Kuwait for $P$. babylonica. However, all the taxonomic studies conducted in Kuwait revealed that $P$. babylonica is the only species of this genus that was identified from this region (Al-Rawi 1987, Boulos and Al-Dosari 1994). Malallah et al. (1997), Malallah and Brown (1999) reported the somatic chromosome number of this species as $2 n=10$ and the gametic number of $n=5$. Although the present study confirmed these previous findings, it demonstrated the existence of aneuploid conditions $(2 n=9,11$, 12 ) in $P$. babylonica. The monosomic condition was found in cells of only one plant among the $P$. babylonica populations studied. The seeds of the aneuploid plants (with 11 and 9 chromosomes) were collected from the same locality and treated the same as no morphological differences were observed among them. These aneuploid plants were detected among so many other euploid plants from the same locality. The most probable origin of these aneuploids seems to be from the spontaneous errors in meiotic process that lead to the failure of pairing and consequently to the unequal distribution of chromosomes (Weber 1983, Wiggers et al. 1990, Sybenga 1992, Kim 1994). It is not 

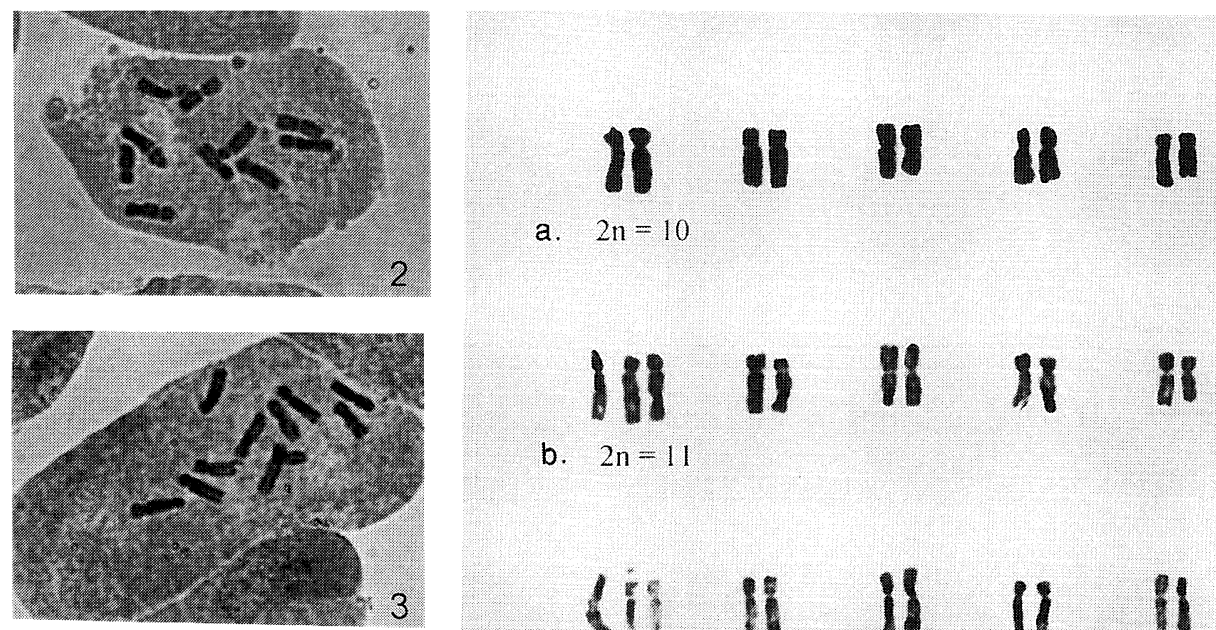

\section{Iif is I| 11 iा}

b. $2 n=11$

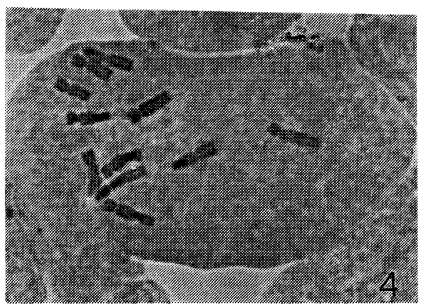
(i)
II
is
II
i1

c. $2 n=11$

\section{IiI II II |I II}

d. $2 n=11$

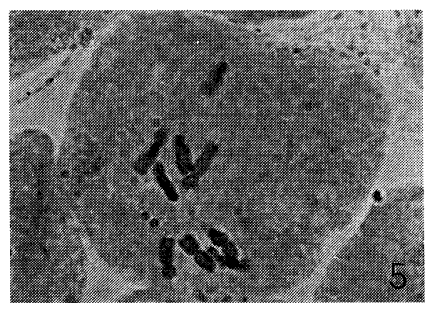

\section{| 11 | 11 |}

e. $2 n=9$
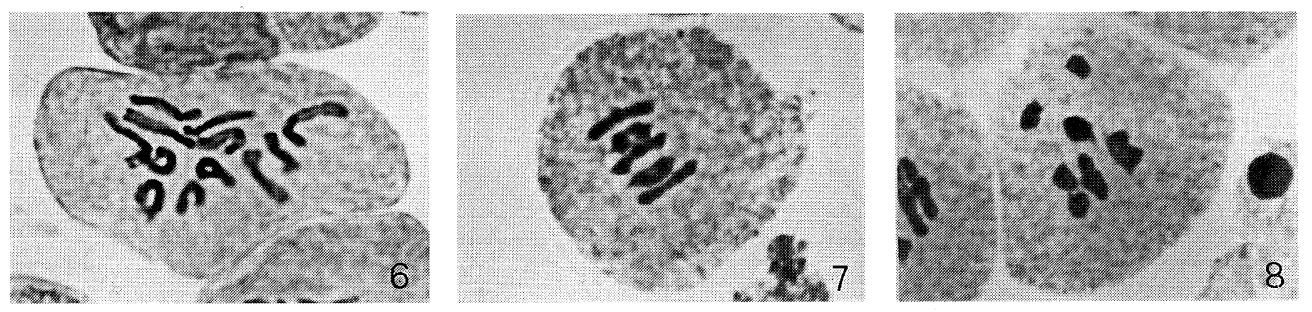

Figs. 1-8. 1) Karyotypes of Picris babylonica with normal and aneuploid conditions. 2) Diploid cell of Picris babylonica $(2 n=10) .3$ and 4) Trisomic state $(2 n=11) .5)$ Monosomic state $(2 n=9)$. 6) Tetrasomic state $(2 n=12) .7)$ PMC showing 5 bivalents. 8) PMC showing 4 bivalents and 2 univalents.

known whether the environmental conditions in the area could lead to such numerical chromosomal aberrations. These aberrations have not been seen in many other plants of the same species from other localities. However, the tetrasomic condition was seen in plant collected in 1993 after the Gulf War, which might be related to the polluted environment at that time because in another study, abnormaliteis were seen in samples collected from the same area during 1992 and 1993 (Malallah et al. 1997). The presence of univalents observed in the pollen mother cells in the present study demonstrates the failure of pairing which might lead to aneuploidy of $P$. babylonica. Because of the 
Table 1. Karyotype analysis of Picris babylonica

\begin{tabular}{|c|c|c|c|c|c|c|c|c|c|c|c|c|}
\hline \multirow{3}{*}{$\begin{array}{c}\text { Karyotype } \\
\text { number } \\
(2 n)\end{array}$} & \multirow{3}{*}{$\begin{array}{l}\text { Arm length } \\
\text { ratio } \\
(\mu \mathrm{m})\end{array}$} & \multicolumn{11}{|c|}{ Chromosome } \\
\hline & & \multirow{2}{*}{$\begin{array}{c}\text { Extra } \\
\text { Chromosome }\end{array}$} & \multicolumn{2}{|c|}{ Pair 1} & \multicolumn{2}{|c|}{ Pair 2} & \multicolumn{2}{|c|}{ Pair 3} & \multicolumn{2}{|c|}{ Pair 4} & \multicolumn{2}{|c|}{ Pair 5} \\
\hline & & & 1 & 2 & 3 & 4 & 5 & 6 & 7 & 8 & 9 & 10 \\
\hline \multirow[t]{5}{*}{ a. 10} & Short arm & & 0.55 & 0.60 & 0.55 & 0.50 & 0.65 & 0.60 & 0.59 & 0.59 & 0.41 & 0.40 \\
\hline & Long arm & & 1.24 & 1.27 & 1.09 & 1.09 & 0.80 & 0.80 & 1.19 & 1.13 & 1.31 & 0.84 \\
\hline & Centromeric index & & 1.79 & 1.87 & 1.64 & 1.59 & 1.44 & 1.39 & 1.78 & 1.72 & 1.72 & 1.24 \\
\hline & L/S Ratio & & 2.28 & 2.13 & 2.00 & 2.20 & 1.23 & 1.33 & 2.02 & 1.92 & 3.19 & 2.12 \\
\hline & Type & & $\mathrm{sm}$ & $\mathrm{sm}$ & $\mathrm{sm}$ & $\mathrm{sm}$ & $\mathrm{m}$ & $\mathrm{m}$ & $\mathrm{sm}$ & $\mathrm{sm}$ & st & $\mathrm{sm}$ \\
\hline \multirow[t]{5}{*}{ b. 11} & Short arm & 0.60 & 0.50 & 0.50 & 0.50 & 0.40 & 0.70 & 0.75 & 0.45 & 0.45 & 0.55 & 0.40 \\
\hline & Long arm & 1.34 & 1.39 & 1.39 & 1.09 & 1.09 & 0.89 & 0.89 & 1.04 & 1.04 & 0.89 & 0.84 \\
\hline & Centromeric index & 1.94 & 1.89 & 1.89 & 1.59 & 1.49 & 1.59 & 1.64 & 1.49 & 1.49 & 1.44 & 1.22 \\
\hline & L/S Ratio & 2.25 & 2.81 & 2.81 & 2.20 & 2.76 & 1.29 & 1.20 & 2.34 & 2.34 & 1.64 & 2.12 \\
\hline & Type & $\mathrm{sm}$ & sm & $\mathrm{sm}$ & $\mathrm{sm}$ & $\mathrm{sm}$ & $\mathrm{m}$ & $\mathrm{m}$ & sm & $\mathrm{sm}$ & $\mathrm{sm}$ & $\mathrm{sm}$ \\
\hline \multirow[t]{5}{*}{ c. 11} & Short arm & 0.70 & 0.84 & 0.80 & 0.55 & 0.55 & 0.70 & 0.84 & 0.45 & 0.50 & 0.60 & 0.55 \\
\hline & Long arm & 1.19 & 1.34 & 1.29 & 1.19 & 1.24 & 1.20 & 1.00 & 1.39 & 1.29 & 1.29 & 1.00 \\
\hline & Centromeric index & 1.89 & 2.19 & 2.09 & 1.74 & 1.79 & 1.89 & 1.84 & 1.84 & 1.79 & 1.89 & 1.54 \\
\hline & L/S Ratio & 1.72 & 1.59 & 1.62 & 2.18 & 2.28 & 1.72 & 1.18 & 3.12 & 2.60 & 2.16 & 1.82 \\
\hline & Type & $\mathrm{sm}$ & $\mathrm{sm}$ & $\mathrm{sm}$ & $\mathrm{sm}$ & $\mathrm{sm}$ & $\mathrm{m}$ & $\mathrm{m}$ & st & $\mathrm{sm}$ & $\mathrm{sm}$ & $\mathrm{sm}$ \\
\hline \multirow[t]{5}{*}{ d. 11} & Short arm & 0.55 & 0.65 & 0.60 & 0.60 & 0.55 & 0.70 & 0.70 & 0.45 & 0.40 & 0.40 & 0.35 \\
\hline & Long arm & 1.34 & 1.44 & 1.33 & 1.33 & 1.39 & 1.00 & 1.00 & 1.28 & 1.05 & 1.00 & 0.83 \\
\hline & Centromeric index & 1.89 & 2.09 & 1.93 & 1.93 & 1.93 & 1.69 & 1.69 & 1.72 & 1.45 & 1.40 & 1.18 \\
\hline & L/S Ratio & 2.46 & 2.24 & 2.23 & 2.23 & 2.54 & 1.44 & 1.44 & 2.86 & 2.66 & 2.51 & 2.37 \\
\hline & Type & $\mathrm{sm}$ & $\mathrm{sm}$ & $\mathrm{sm}$ & $\mathrm{sm}$ & $\mathrm{sm}$ & $\mathrm{m}$ & $\mathrm{m}$ & $\mathrm{sm}$ & $\mathrm{sm}$ & $\mathrm{sm}$ & $\mathrm{sm}$ \\
\hline \multirow[t]{6}{*}{ e. 9} & Short arm & & & 0.60 & 0.55 & 0.50 & 0.70 & 0.65 & 0.45 & 0.40 & 0.35 & 0.40 \\
\hline & Long arm & & & 1.20 & 1.34 & 1.20 & 0.80 & 0.84 & 0.84 & 0.94 & 0.94 & 0.89 \\
\hline & Centromeric index & & & 1.79 & 1.89 & 1.69 & 1.49 & 1.49 & 1.29 & 1.34 & 1.29 & 1.29 \\
\hline & L/S Ratio & & & 2.00 & 2.46 & 2.41 & 1.15 & 1.31 & 1.89 & 2.38 & 2.72 & 2.25 \\
\hline & Type & & & $\mathrm{sm}$ & $\mathrm{sm}$ & $\mathrm{sm}$ & $\mathrm{m}$ & $\mathrm{m}$ & $\mathrm{sm}$ & $\mathrm{sm}$ & $\mathrm{sm}$ & $\mathrm{sm}$ \\
\hline & S.E. for Total Length & 0.01 & 0.05 & 0.05 & 0.07 & 0.08 & 0.08 & 0.08 & 0.1 & 0.08 & 0.11 & 0.06 \\
\hline
\end{tabular}

$\mathrm{m}=$ median, $\mathrm{sm}=$ submedian, $\mathrm{st}=$ subterminal.

relative close lengths of all chromosomes of this species and depending only on the photographs, it is unknown whether the univalents are the members of the first pair or not. Nevertheless the involvement of the first pair is strongly indicated by karyotype analyses shown in Table 1 and Fig. 1. The failure of pairing was previously reported by El-Bayoumi (1973) who found in addition to univalents, a reduced chiasma frequency (1.12) per bivalent.

Oberprieler and Vogt (1993) reported that the root tips of Picris saharae showed $2 n=10+1 \mathrm{~B}$, indicating the presence of one $\mathrm{B}$ chromosome in addition to the diploid value of 10 . The origin and development of B chromosome were discussed in several studies (Brown 1972, Brown and Bertke 1974, White 1973, Dyer 1979). Those studies concluded that the non-disjunction (resulting from failure of pairing) and the dysploid, (where the number of chromosomes in the genome is altered with no significant change in the genotype) create the progenitors B chromosome. Wild populations of many plant species contain B chromosomes that are mostly heterochromatic and with infrequent presence in somatic tissue.

Aneuploidy can generally play an important role in plant evolution and stepwise progression of chromosome number. Detailed studies of aneuploidy and changes associated with them have provided valuable chromosomal information to botanists and taxonomists of various flowering plant groups. Aneuploidy may lead to creation of new chromosome numbers other than the known basic 
one; a change which may be associated with new characteristics that could be of some adaptive value. Such a process has been proposed to be effective in the evolution in the genus Mikania of the Asteraceae (Ruas Claudette and Aguiar-Perecin Margarida 1997). In Family Asteraceae, aneuploid plants were found in Aster occidentalis and were assessed for morphological variability and geographical distribution (Allen Geraldine 1984). Kim (1994) discussed aneuploidy, including their origin and possible role in the evolution of the 2 families Asteraceae and Onagraceae. An evolutionary trend involving chromosomal rearrangement in addition to polyploidy and aneuploidy has also been suggested for Stevia in southern Brazil (Frederico Andriana et al. 1996). Therefore, it would be interesting to illustrate the importance of aneuploidy in evolution of $P$. babylonica.

A better understanding for the causes and the consequences of incidences of aneuploidy, particularly in relation to evolutionary processes in natural populations of plants, is urgently needed. This goal may be realized through advanced analysis by modern methods of cytogenetics and biochemistry, and if achieved, it will certainly help to broaden our knowledge on the cytoevolutionary processes, that occur in flowering plants.

The observation of different chromosome numbers in the some plants of $P$. babylonica is documented here for the first time; this represents a case of aneusomaty, which refers to the presence of somatic cells with varying chromosome numbers. Aneusomaty has also been observed in sunflower (Helianthus annuus L.), mainly in root and shoot tips or during embryo development (Cremonini and Cavallini 1986, Cavallini and Cremonini 1985, 1987). In this case, aneusomaty was found to progressively decrease in the course of plant growth and disappear before meiosis commenced in the anthers. Whether a similar process of selection against aneuploid cells during plant development occur in the aneuploids of $P$. babylonica is currently unknown in the documented aneuploids in the present work as they were found accidentally.

In order to further assess the extent of aneuploidy in Kuwait populations of P. babylonica and its effects on meiosis, fertility and other selected characters, an intensive cytological examination of additional Picris populations is currently underway.

An interesting thing was found in 6 specimens of $P$. babylonica in that all the inflorescence composed exclusively of tubular flowers. The specimens were found in several occasions during 1997-1999 and now they are deposited in KTUH. Unfortunately, none of them contain buds or seeds to examine the cytological bases of this morphological difference. It is worthwhile to mention that this species shows flowers with 3 types of heads, homocarpus, heterocarpus and mixture of both as shown by Mandaville (1990) who stated that all of these types should be treated as forms of P. babylonica. However, the dissecting tubular flowers showed abnormal ovaries, which might lead to unviable seeds.

\section{Acknowledgement}

We would like to thank Mr. Husni Muhammed (Dept. of Biol. Sci., Kuwait University) for his technical assistance. This research is supported by Kuwait University as project \#SO 078.

\section{References}

Allen Geraldine, A. 1984. Morphological and cytological variations in the Western North American Aster occidentalis complex (Asteraceae). Systematic Bot. 9: 175-191.

Al-Rawi, A. 1987. Flora of Kuwait Vol. 2. Kuwait University/Alden Press, Oxford, I-xiii, 225-455.

Boulos, L. and Al-Dosari, M. 1994. Checklist of the Flora of Kuwait. J. Univ. Kuwait. 21, pp. 203-218.

Brown, W. V. 1972. Text Book of Cytogenetics. The C.V. Mosby Company, Saint Louis, USA. pp. 129-133.

— and Bertke, E. M. 1974. Text Book of Cytology. The C.V. Mosby Company, Saint Louis, USA. pp. 377.

Cavallini, A. and Cremonini, R. 1985. Aneuosomaty in sunflower (Helianthus annus L.). Zeitschrift für Pflanzenzüchtung 95: 118-124. 
— and - 1987. Chromosomal variability in the sunflower (Helianthus annus L.). Genetica Agraria 41: 291-292.

Cremonini, R. and Cavallini, A. 1986. Origin and fate of aneuosomaty in sunflower (Helianthus annus L.). Plant Breeding 97: 89-92.

Darlington, C. D. and Wylie, A. P. 1955. Chromosome Atlas of Flowering Plants. George Allen \& Unwin, London. pp. 247.

Dyer, A. F. 1979. Investigating Chromosomes. Edward Arnold (Publishers) Ltd., London, U.K. pp. 92-93.

El-Bayoumi, A. 1973. A study of meiosis on some wild plant species from Kuwait. Cytologia 38: 357-361.

Frederico Andriana, P., Ruas Paulo, M., Marin-Moralea Maria, M., Ruas Claudete, F. and Nakajima Jimi, N. 1996. Chromosome studies in some Stevia cv. (Compositae) species from Southern Brazil. Braz. J. Genet. 19: 605-609.

Khush, G. S. 1970. Aneuploidy. Academic Press, New York.

- 1973. Cytogenetics of Aneuploids. Academic Press, New York and London.

— and Rick, C. M. 1966. The origin, identification and cytogenetic behavior of tomato monosomics. Chromosoma 18: 407-420.

Kim, I. 1994. Aneuploidy in flowering plants: Asteraceae and Onagraceae. Korean J. Plant Taxonomy 24: $265-278$.

Malallah, G., Afzal, M., Murin, G., Murin, A. and Abraham, D. 1997. Genotoxicity of oil pollution on some species of Kuwaiti flora. Biologia (Bratislava) 52/1: 61-70.

- and Brown, G. 1999. Determination of chromosome number of Kuwaiti flora I. Cytologia 64: 181-196.

Mandaville, J. P. 1990. Flora of Eastern Saudi Arabia. Kegan Paul Internationa. London, England. pp. 317-318.

Oberprieler, C. and Vogt, R. 1993. Chromosome numbers of North African phanerogams. II. Willdenowia 23: $211-138$.

Rick, C. M. 1971. Some Cytogenetic Features of the Genome in Diploid Plant Species. In Kimber, G. and Reidei, G. P. (eds.). Stadler Genetics Symposia Vols. 1 and 2. Univ. Missouri Agr. Exp. Sta., Columbia, MO.

- and Notani, N. K. 1961. The tolerance of extra chromosomes by primitive tomatoes. Genetics 46: 1231-1235.

Ruas Claudette, F. and Aguiar-Perecin Margarida, L. R. 1997. Chromosome evolution in the genus Mikania (Compositae). Amer. J. Bot. 84: 1156-1173.

Sybenga, J. 1992. Cytogenetics in Plant Breeding. Springer-Verlag. p. 166.

Wang, Z. X. and Iwata, N. 1996. The origin, identification, and plant morphology of five rice monosomics. Genome 39: 528-534.

Weber, D. F. 1983. Monosomic Analysis in Diploid Crop Plants. In: Swaminathan, M. S., Gupta, P. K. and Sinha, U. (eds.). Cytogenetics of Crop Plants. MacMillan India, Dehli. pp. 531-378.

White, M. J. D. 1973. The Chromosome. Chapman and Hall, London, U.K. pp. 160-171.

Wiggers, R. J., Starr, J. L. and Prices, H. J. 1990. DNA content and variation in chromosome number in plant cells affected by Meloidogyne incognita and M. arenaria. Phytopathology 80: 1391-1395. 